\title{
The importance of tidal and lateral asymmetries in stratification to residual circulation in partially mixed estuaries
}

\author{
ME Scully \\ Carl T. Friedrichs \\ Virginia Institute of Marine Science
}

Follow this and additional works at: https://scholarworks.wm.edu/vimsarticles

Part of the Aquaculture and Fisheries Commons

\section{Recommended Citation}

Scully, ME and Friedrichs, Carl T., "The importance of tidal and lateral asymmetries in stratification to residual circulation in partially mixed estuaries" (2007). VIMS Articles. 1013.

https://scholarworks.wm.edu/vimsarticles/1013 


\title{
The Importance of Tidal and Lateral Asymmetries in Stratification to Residual Circulation in Partially Mixed Estuaries*
}

\author{
Malcolm E. SCULly \\ Woods Hole Oceanographic Institution, Woods Hole, Massachusetts \\ CARL T. FRIEDRICHS \\ Virginia Institute of Marine Science, The College of William and Mary, Gloucester Point, Virginia
}

(Manuscript received 2 August 2005, in final form 27 September 2006)

\begin{abstract}
Measurements collected in the York River estuary, Virginia, demonstrate the important impact that tidal and lateral asymmetries in turbulent mixing have on the tidally averaged residual circulation. A reduction in turbulent mixing during the ebb phase of the tide caused by tidal straining of the axial density gradient results in increased vertical velocity shear throughout the water column during the ebb tide. In the absence of significant lateral differences in turbulent mixing, the enhanced ebb-directed transport caused by tidal straining is balanced by a reduction in the net seaward-directed barotropic pressure gradient, resulting in laterally uniform two-layer residual flow. However, the channel-shoal morphology of many drowned river valley estuaries often leads to lateral gradients in turbulent mixing. Tidal straining may then lead to tidal asymmetries in turbulent mixing near the deeper channel while the neighboring shoals remain relatively well mixed. As a result, the largest lateral asymmetries in turbulent mixing occur at the end of the ebb tide when the channel is significantly more stratified than the shoals. The reduced friction at the end of ebb delays the onset of the flood tide, increasing the duration of ebb in the channel. Conversely, over the shoal regions where stratification is more inhibited by tidal mixing, there is greater friction and the transition from ebb to flood occurs more rapidly. The resulting residual circulation is seaward over the channel and landward over the shoal. The shoal-channel segregation of this barotropically induced estuarine residual flow is opposite to that typically associated with baroclinic estuarine circulation over channel-shoal bathymetry.
\end{abstract}

\section{Introduction}

The understanding of tidally averaged residual circulation is fundamental to the study of estuarine processes. The classic representation of the two-layer estuarine exchange flow was represented by Pritchard (1956) as the balance between the seaward-directed barotropic pressure gradient, the landward-directed baroclinic pressure gradient, and the stress divergence. The internal friction associated with the exchange flow is often parameterized in terms of a vertically and tid-

\footnotetext{
* Virginia Institute of Marine Science, College of William and Mary, Contribution Number 2744.
}

Corresponding author address: Malcolm Scully, Woods Hole Oceanographic Institution, Mail Stop 10, Woods Hole, MA 02543. E-mail: mscully@whoi.edu ally averaged eddy viscosity acting on the tidally averaged vertical velocity shear. This representation of estuarine circulation has been the cornerstone for the classical understanding of estuarine dynamics. However, the use of a tidally averaged mixing coefficient may often be inappropriate in characterizing the basic forcing driving tidally averaged residual circulation in estuarine systems where there are significant spatial and temporal asymmetries in turbulent mixing.

In many estuarine systems, the interaction between the vertical tidal shear and the longitudinal density gradient can lead to tidal asymmetries in density stratification. This process, known as tidal straining (Simpson et al. 1990), favors the development of stratification during ebb tides and the destruction of stratification during the flood and can lead to significant tidal asymmetries in vertical mixing (Stacey et al. 1999; Geyer et al. 2000; Rippeth et al. 2001). Jay and Musiak (1994)

DOI: $10.1175 / \mathrm{JPO} 3071.1$ 
suggested that tidal asymmetries in vertical mixing associated with tidal straining could play an important role in generating residual circulation in estuaries. They argued that the reduction of tidal mixing during the ebb tide resulted in an internal tidal asymmetry that could generate a two-layer tidally averaged residual circulation qualitatively similar to a baroclinically driven exchange flow. Consistent with Jay and Musiak's results, Stacey et al. (2001) kinematically described the twolayer residual circulation in northern San Francisco Bay as the barotropic response to tidal asymmetries in vertical mixing. In a study carried out in the Hudson River estuary, Geyer et al. (2000) also observed tidal asymmetries in the vertical mixing coefficients associated with tidal straining, but concluded that the tidally averaged estuarine circulation was not fundamentally affected by this internal asymmetry. In a companion paper, however, Trowbridge et al. (1999) found the relationship between bottom stress and the near-bed velocity shear in the Hudson systematically departed from the law of the wall during ebb tides, consistent with greater stratification due to tidal straining. Trowbridge et al. (1999) hypothesized that the departure from the law of the wall on ebb was not due to local stratification, but caused by overlying stratification remotely damping the near-bed turbulent length scale. Similar findings were presented by Scully and Friedrichs (2003), who demonstrated significant damping of near-bed turbulence by nonlocal, overlying stratification in the York River estuary.

These previous studies provide a somewhat contradictory view of the effect that tidal asymmetries in mixing have on estuarine residual circulation. While Jay and Musiak (1994) and Stacey et al. (2001) suggest tidal straining of the density field enhances up-estuary residual flow near the bed, Geyer et al. (2000) concluded that asymmetries in vertical mixing had little impact on the near-bed residual circulation. Trowbridge et al. (1999) and Scully and Friedrichs (2003) suggested that tidal straining of the density field often leads to increased velocity shear on ebb near the bed, but did not document bottom intensification of the flow during flood due to convective mixing. Their results suggest that given perfectly symmetric forcing, tidal straining would favor down-estuary residual flow if there were no adjustment of the net barotropic pressure gradient.

In addition to the variations in turbulent mixing caused by temporal changes in stratification, many estuarine systems exhibit spatial gradients in mixing caused by lateral bathymetric variability. The impact of bathymetry on residual estuarine circulation has been addressed analytically by a number of authors (Wong 1994; Kasai et al. 2000; Valle-Levinson et al. 2003).
However, their analytical approach uses a spatial and temporally constant eddy viscosity and thus cannot account for asymmetries in turbulent mixing. Only the analytical model of Friedrichs and Hamrick (1996) attempted to account for lateral variations in mixing by assuming the eddy viscosity scaled with depth. Drowned river valley estuaries often have channelshoal morphologies, with marked lateral variations in density stratification. Lateral mixing fronts often form at breaks in topography, separating the relatively well mixed water on the shoal from the more stratified waters over the channel (Huzzey and Brubaker 1988). In contrast to the approach suggested by Friedrichs and Hamrick (1996), the absence of stratification over the shoal may enhance turbulent mixing relative to the more stratified channel. Despite the fact that lateral variability in stratification in many systems may exceed temporal variations arising from tidal straining, its role in modulating residual circulation has been largely ignored.

In this paper, measurements collected at two laterally adjacent locations are used to examine the forces driving residual circulation in the York River estuary. The observational and analytical methods are described in section 2 and the results are presented in section 3 . The results include direct measurements that document tidal asymmetries in turbulent mixing. Lateral asymmetries in turbulent mixing are inferred from stress estimates based on the dominant terms in the axial momentum balance. Last, results from a numerical experiment utilizing $k$-epsilon turbulence closure are presented to examine in more detail the physical mechanisms that create residual flows in estuaries experiencing tidal and lateral asymmetries in stratification. The results are discussed in section 4 , and conclusions are presented in section 5.

\section{Methods}

\section{a. Environmental setting and observations}

Observations were collected in the mesohaline portion of the York River estuary during the winter of 2003/04 (Fig. 1). The York River is a partially mixed subestuary of the Chesapeake Bay that forms at the confluence of the Mattaponi and Pamunkey Rivers. Most of the York River is characterized by a main channel with an approximate depth of $10 \mathrm{~m}$, flanked by broad shoals with a mean depth of approximately $4 \mathrm{~m}$. Although the mean tidal range is only about $0.7 \mathrm{~m}$, tidal currents are energetic with surface currents reaching over $1 \mathrm{~m} \mathrm{~s}^{-1}$ during spring tidal conditions. Both salinity and temperature exhibit significant seasonal variability; however, the density gradient is nearly always 


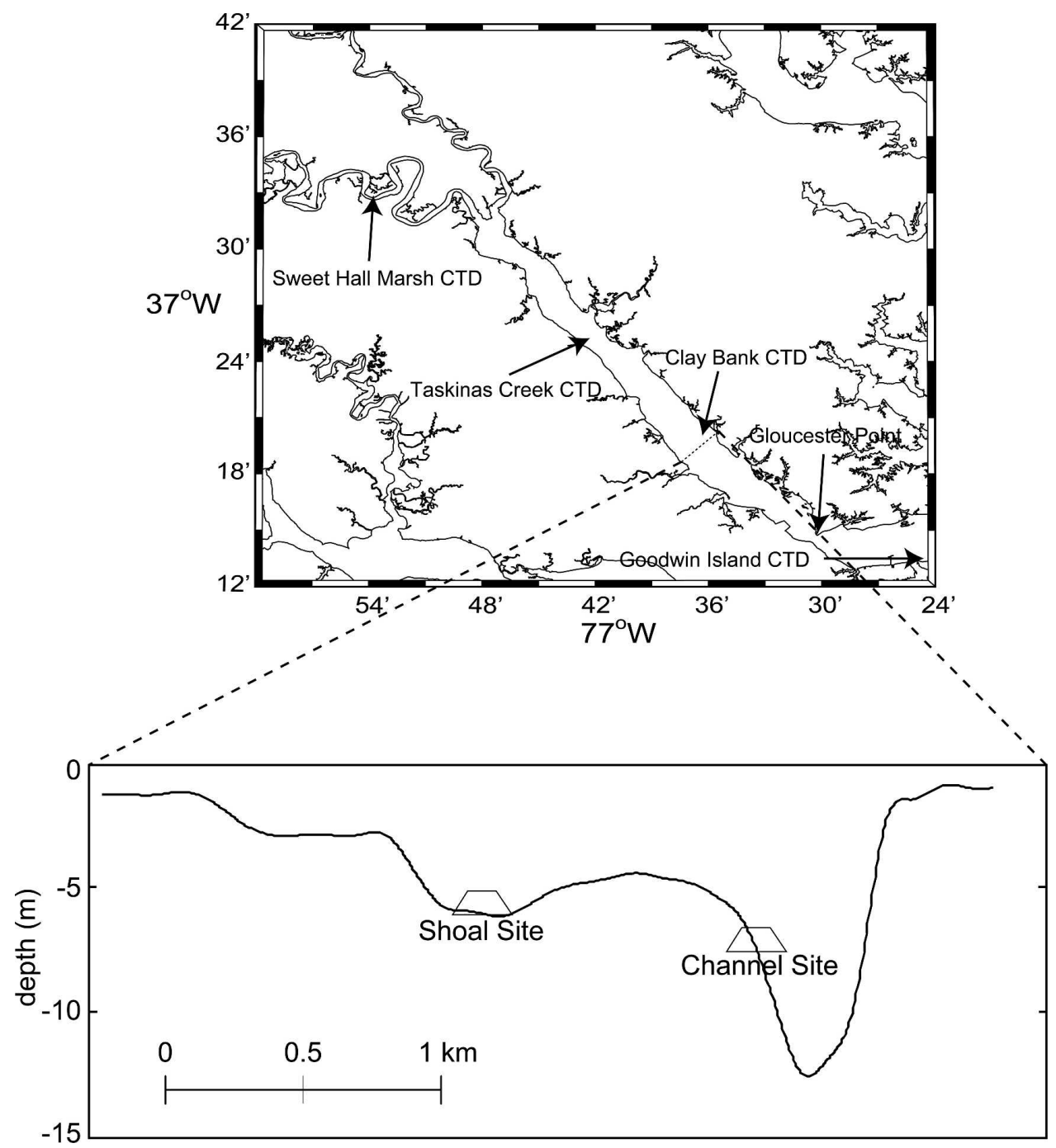

FIG. 1. Map of study area, York River estuary, VA, with estuarine cross section at "channel" and "shoal" deployment locations. Also shown are locations of the CBNERR CTD sites.

dominated by gradients in salt. Top-to-bottom salinity stratification can range from well mixed to greater than 12 psu.

During the winter of 2003/04, instrumentation was maintained at two laterally adjacent locations in the estuarine cross section near Clay Bank, located roughly $13 \mathrm{~km}$ up-estuary from Gloucester Point. At this location in the York River, the main channel of the estuary is located on the northeastern side of the river with a maximum depth of approximately $10 \mathrm{~m}$. A broad shoal extends to the southwest of the main navigational channel with a mean depth of less the $5 \mathrm{~m}$ and a maximum depth of approximately $6.5 \mathrm{~m}$. Instruments were deployed along the southwestern side of the main channel at a water depth of approximately $7 \mathrm{~m}$ ("channel" site) to avoid interfering with navigation, and at the deepest location within the southwestern shoals at a water depth of roughly $6 \mathrm{~m}$ ("shoal" site). Although the instrumented locations had a similar depth, for the purposes of this paper we assume that they are broadly representative of the deeper channel and shallower shoal regions found in the cross section.

During the experiment, detailed velocity measurements were collected by four Sontek acoustic Doppler velocimeters (ADVs), an RDI $1200-\mathrm{kHz}$ acoustic Doppler current profiler (ADCP), and a Sontek 1500$\mathrm{kHz}$ acoustic Doppler profiler (ADP). The four ADVs were mounted on a benthic boundary layer tripod deployed at the channel site to provide high-resolution velocity measurements at discrete elevations over the lowest $1.2 \mathrm{~m}$ of the water column. The ADVs were mounted $0.10,0.43,0.76$, and $1.1 \mathrm{~m}$ above the bed 
(mab), on an arm of the tripod that was rotated perpendicular to the dominant orientation of the York River channel. The ADVs at 0.43 and 0.76 mab did not function properly and will not be discussed. The ADVs collected three-dimensional velocity measurements in 5 -min bursts once an hour at a sampling frequency of 5 Hz. The $1200-\mathrm{kHz}$ ADCP was deployed immediately adjacent to the tripod at the channel site and collected vertical profiles of current velocity in $0.50-\mathrm{m}$ bins. The ADCP sampled at roughly $1 \mathrm{~Hz}$ and collected one 10min burst every hour. The $1500-\mathrm{kHz}$ ADP was deployed at the shoal site and sampled at a rate of $1 \mathrm{~Hz}$ averaged over 1-min bursts to provide vertical profiles of current velocity in 0.25 -m bins.

Three YSI 6000 conductivity-temperature-depth sensors (CTDs) were mounted on the tripod at the channel site at $0.10,0.41$, and $1.4 \mathrm{mab}$ and collected pressure, salinity, and temperature every $30 \mathrm{~min}$. A mooring that consisted of an YSI 6000 CTD and an InterOcean S4 current meter, outfitted with a CTD, was located immediately adjacent to the tripod at the channel site. The CTD and S4 on the mooring were located 2.8 and $3.4 \mathrm{mab}$, respectively. At the shoal site, two YSI 6600 CTDs located 0.10 and $1.5 \mathrm{mab}$ and an InterOcean S4 sensor with a CTD located 3.5 mab were deployed immediately adjacent to the ADP. In addition to the field instrumentation deployed as part of this experiment, the Chesapeake Bay National Estuarine Research Reserve (CBNERR) maintains four YSI 6600 datasondes year-round along the York River estuary as shown in Fig. 1. Each sensor is mounted on a fixed platform immediately below mean low water and measures a variety of environmental parameters every 15 min. In this paper, we use the CBNERR pressure sensor data to estimate the along-channel barotropic pressure gradient.

\section{b. Data analysis}

The primary focus of this paper is to examine how asymmetries in turbulent mixing associated with temporal and spatial gradients in density stratification impact the tidally averaged residual circulation. Direct measurements of stress are available from the ADV data collected at the channel site. To calculate stress from the ADV data, the flow measurements in each burst were first rotated vertically such that no mean vertical velocity was present. Flow measurements were then rotated horizontally into the predominant alongchannel direction. Reynolds stress calculations were made using the covariance method as described by Kim et al. (2000), where

$$
\tau_{b}=\rho\left\langle u^{\prime} w^{\prime}\right\rangle .
$$

The angled brackets indicate time averaging, and $u^{\prime}$ and $w^{\prime}$ represent the turbulently fluctuating components of the along-channel and vertical velocities, respectively. Although there were no direct measurements of stress at the shoal site, estimates of stress can be obtained from the dominant terms in the axial momentum balance (Geyer et al. 2000; Winant and Gutierrez de Velasco 2003). Neglecting rotation and the advective terms, the along-channel momentum balance can be written approximately as

$$
\frac{\partial u}{\partial t}=-g \frac{\partial \eta}{\partial x}+\frac{g}{\rho} \int \frac{\partial \rho}{\partial x} d z+\frac{1}{\rho} \frac{\partial \tau}{\partial z},
$$

where $u$ is the along-estuary velocity, $g$ is the acceleration of gravity, $\eta$ is the sea surface elevation anomaly, $x$ is the horizontal coordinate (positive landward), $\rho$ is the density of water, $\tau$ is the Reynolds stress, and $z$ is the vertical coordinate (positive upward). We followed the methods of Geyer et al. (2000) and vertically integrated Eq. (2) to solve for the vertical profile of the effective stress $(\tau)$, assuming that $\partial \rho / \partial x$ to be independent of $z$. This assumption was generally consistent with data collected during two longitudinal hydrographic surveys conducted during the experiment.

The acceleration term $(\partial u / \partial t)$ was easily determined from both the ADCP and ADP data. The barotropic pressure gradient was calculated from the difference between the pressure sensors deployed by CBNERR at the Sweet Hall Marsh and Goodwin Island locations. Although they were separated by the greatest distance of the four pressure sensors, the instrumented cross section was located nearly equidistant from these two sensors. In addition, we previously compared the alongchannel barotropic pressure gradient calculated from all possible combinations of these four CBNERR sensors that coincided with data collected by tide gauges during an experiment in 2002 (Scully and Friedrichs 2003; Simpson et al. 2005). The gradient measured between the Sweet Hall Marsh and Goodwin Island CBNERR stations best matched the well-constrained local tide gauge data collected during 2002. When calculating the barotropic pressure gradient from the CBNERR pressure sensor data, there was an unknown offset between the two sensors due to their fixed heights relative to the local geopotential surface. Consistent with methods of Geyer et al. (2000), this difference was determined by requiring the zero crossings of the momentum-integral estimates of near-bed stress to occur at the times of the zero crossings of the near-bed velocity.

In calculating the baroclinic pressure gradient, the along-channel salinity gradient was estimated using the 
S4 data from the channel and shoal sites based on the local salt conservation equation, ignoring lateral advection and vertical turbulent flux:

$$
\frac{\partial S}{\partial x}=-\frac{1}{u} \frac{\partial s}{\partial t} .
$$

The relatively minor contribution of the axial temperature gradient was not included in the estimate of the baroclinic pressure gradient. The estimates of $\partial s / \partial x$ using Eq. (3) were low-passed filtered to remove the highfrequency noise associated with this method. The separate estimates from the two adjacent locations were then averaged, assuming that the along-channel density gradient did not vary significantly in the across-channel direction. The time series of $\partial s / \partial x$ obtained in this manner has a temporal variability consistent with that derived from the CBNERR data. Estimates from the various CBNERR stations could not be used directly because of a number of issues, including 1) the presence of freshwater at the Sweet Hall Marsh location; 2) lateral density differences between Clay Bank and Taskinas Creek; and 3) salinity gradient reversals near the mouth of the estuary. In calculating the baroclinic pressure gradient for both experiments, we assumed that $\partial \rho / \partial x$ does not vary with depth. Although there may be some errors in both our estimate of the barotropic and baroclinic pressure gradients, these errors have a similar impact on the stress estimates at each across-channel location because it is unlikely that there are persistent lateral differences in either $\partial \eta / \partial x$ or $\partial \rho / \partial x$.

In integrating Eq. (2), the surface stress was set equal to the wind stress calculated using the bulk formula of Large and Pond (1981). Wind data were obtained from the Sewell's Point meteorological station maintained by the National Oceanic and Atmospheric Administration (NOAA), located roughly $36 \mathrm{~km}$ southeast of Gloucester Point. The coordinate system was rotated $30^{\circ}$ west of north so that the winds conform to the main axis of the York River. With the relatively moderate winds observed during the experiment, the momentum estimates of internal stress were relatively insensitive to the inclusion of the surface wind stress. However, the wind plays an important role in modulating both the tidally averaged barotropic pressure gradient and the degree of salinity stratification, as described by Scully et al. (2005).

\section{Results}

\section{a. Observations}

The 2003/04 experiment took place during a period of elevated rainfall. Discharge from the York River tributaries for December 2003 was, on average, nearly 3 times the 60-yr average (Fig. 2a). The experiment spanned approximately 30 days, covering the full spring-neap tidal cycle. The spring-neap cycle was apparent in the depth-averaged current magnitude measured at the channel site (Fig. 2b). With the elevated river discharge, there was persistent vertical density stratification throughout much of the experiment at both the channel and shoal sites, especially during neap tide (Fig. 2c). The vertical stratification exceeded $2 \mathrm{~kg}$ $\mathrm{m}^{-4}$ on several occasions at both locations, and median values of stratification measured between the uppermost and lowermost sensors were 0.88 and $0.58 \mathrm{~kg} \mathrm{~m}^{-4}$ at the channel and shoal sites, respectively. In addition, significant tidal asymmetries in stratification were observed at both locations. At the channel site, the median stratification on flood and ebb was 0.81 and $0.94 \mathrm{~kg}$ $\mathrm{m}^{-4}$, respectively. The asymmetry had the opposite sense at the shoal site, where the flood was actually more stratified on average than the ebb $(0.65$ and 0.53 $\left.\mathrm{kg} \mathrm{m}^{-4}\right)$. This pattern of tidal asymmetry led to the greatest lateral asymmetry in stratification during the ebb tide, which significantly impacted the estuarine dynamics as discussed below. At both locations, the overall degree of stratification also was modulated by the advective effect of wind-driven circulation (Scully et al. 2005).

The subtidal near-bed currents at both sites exhibited significant variability (Fig. 2d). However, a consistent pattern emerged; on average, the currents tended to be more seaward directed at the channel site than at the shoal site, particularly during spring tidal conditions. This pattern was seen clearly in the velocity profiles collected by the ADCP and ADP. Figure 3 shows the velocity profiles collected at each site, averaged separately over neap and spring tidal conditions. For all cases, the tidally averaged along-channel velocity profiles demonstrated vertical shear consistent with the classic view of estuarine circulation. However, there was significant lateral shear during spring tidal conditions when the currents at the shoal site were relatively more landward directed than at the channel site. It is important to note that while the depth at the two sites was roughly the same, the deployments at the channel site were not located at the deepest point in the main channel to avoid interfering with shipping traffic. As a result, the velocity profiles at the channel site did not capture the landward-directed residual flow necessary to conserve mass at the subtidal time scale. We assume that this residual inflow occurred over the deepest portion of the channel to the east of our "channel" location.

Previous authors have documented that the presence of vertical density stratification causes excess shear 
a) York River Discharge

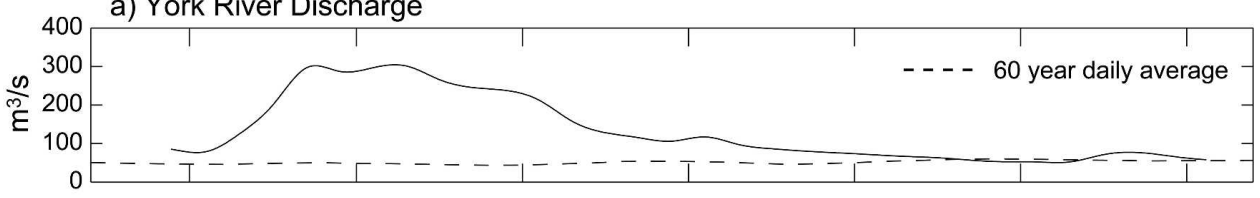

b) Depth-averaged current magnitude (Channel Site)
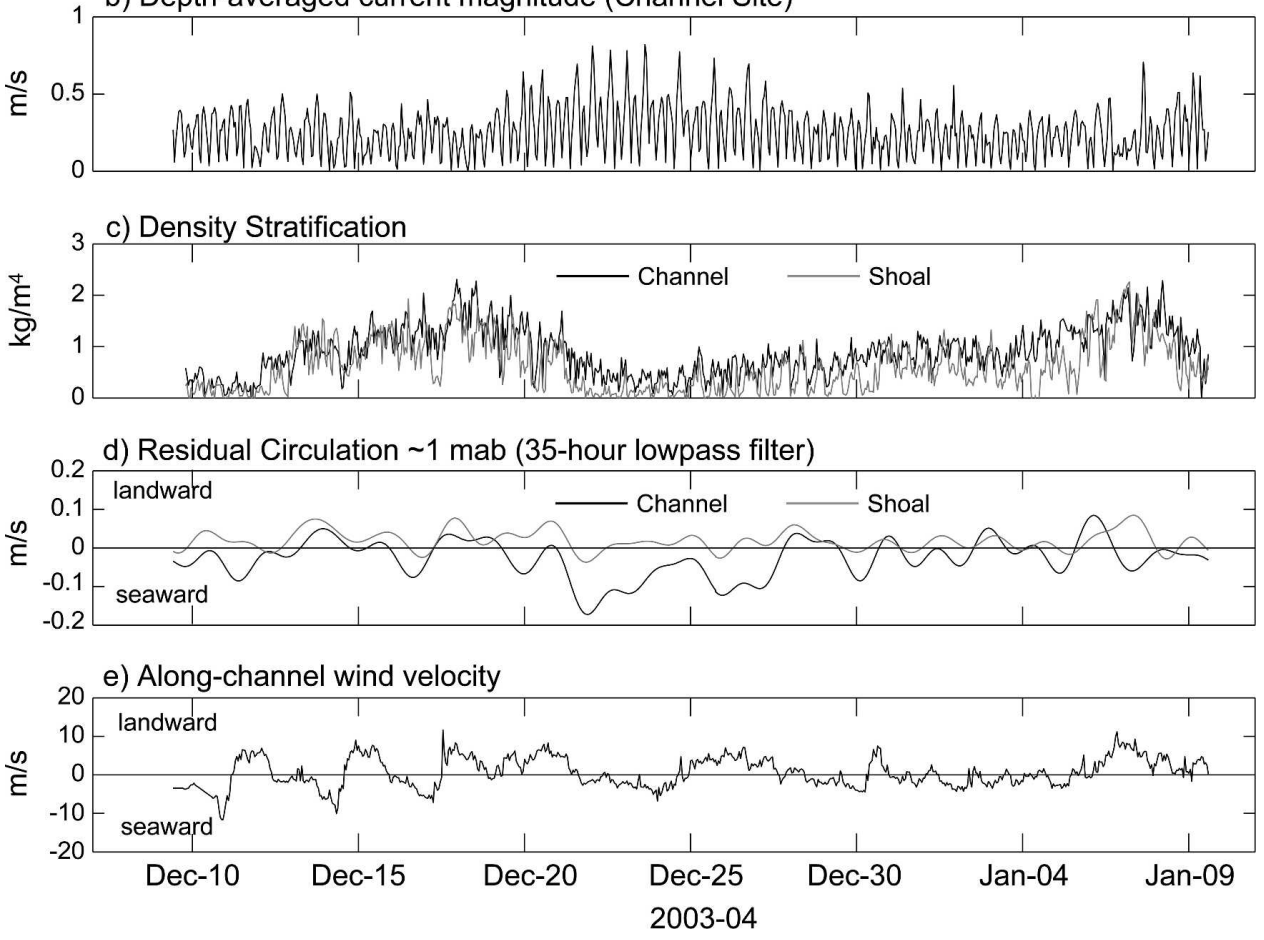

FIG. 2. Time series data December 2003-January 2004: (a) combined daily river discharge from the U.S. Geological Survey's Mattaponi and Pamunkey gauging stations, with 60-yr daily average; (b) depth-averaged current magnitude measured by ADCP at the channel site; (c) density stratification measured between the highest and lowest CTDs at the channel site (dark line) and the shoal site (light line); (d) 35-h low-pass-filtered near-bed currents from the lowest bin of the ADCP at the channel site (dark line) and ADP at the shoal site (light line); (e) along-channel wind speed measured at NOAA's Sewell's Point station (positive values indicate up-estuary-directed wind).

relative to the Prandtl-Karman law-of-the-wall relationship (e.g., Smith and McLean 1977; Soulsby and Dyer 1981; Friedrichs et al. 2000). For purely symmetric barotropic forcing, it follows that the increased shear caused by the increased stratification on the ebb tide due to tidal straining would lead to a greater departure from the law of the wall and (in the absence of a net barotropic pressure gradient) favor down-estuary residual flow. The shear $(\partial u / \partial z)$ in an unstratified boundary layer is expected to follow the law of the wall, given as

$$
u_{*}=\kappa z \frac{\partial u}{\partial z}
$$

where $u_{*}$ is the shear velocity, $\kappa$ is von Kármán's constant (0.41), and $z$ is the height above the bed. This relationship can be evaluated using the ADV data collected at the channel location. Because our estimate of shear is based on velocity measured at two discrete locations, Eq. (4) is rewritten to account for this finite difference as

$$
u_{*}=\frac{\Delta U \kappa}{\log \left(z_{2} / z_{1}\right)} .
$$

The observed velocity difference $(\Delta U)$ was simply calculated by differencing the along-channel velocity from the two functioning ADVs at the channel site, $u_{*}$ $\left(\left\langle u^{\prime} w^{\prime}\right\rangle^{1 / 2}\right)$ was calculated from the stress measured by the lowest $\mathrm{ADV}$ sensor (0.10 mab), and $z_{1}$ and $z_{2}$ are the heights of the lowest and highest ADVs, respectively. Figure 4 plots $\Delta U \kappa / \log \left(z_{2} / z_{1}\right)$ as a function of $u_{*}$. Although the data were noisy, they exhibited a roughly 

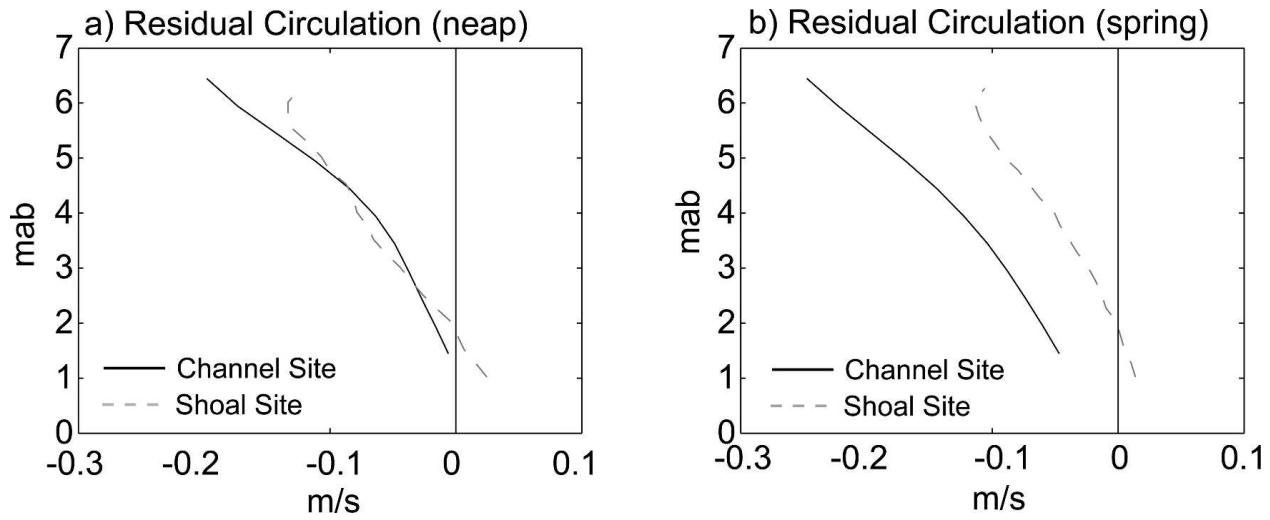

FIG. 3. Depth-averaged along-channel velocity profiles for (a) neap and (b) spring tidal conditions measured by the ADCP at the channel site (solid line) and ADP at the shoal site (dashed line).

linear relationship with an intercept of approximately zero (regression to all data resulted in slope of 1.1 and intercept of -0.0016). In the atmospheric literature, the ratio of $\kappa z \partial u / \partial z$ to $u_{*}$ (defined as $\phi_{m}$ ) is often used to quantify the departure from the law of the wall (e.g., Businger et al. 1971). To estimate $\phi_{m}$, we fit the data in Fig. 4 with a least squares regression. Flood and ebb data were fit separately, the regression was forced through the origin, and all data where the sign of the near-bed velocity and $u_{*}$ were opposite were excluded. As a result, $85 \%$ of the data were used in the regression. The regression analysis yielded values of $\phi_{m}$ of 1.0 and 1.2 for flood and ebb. This result is largely consistent with the results of Trowbridge et al. (1999), as well as with the observed tidal asymmetries in stratification at the channel site.

To more clearly demonstrate that the near-bed shear is impacted by the presence of density stratification, Fig. 5 shows the time series of $\phi_{m}$ in comparison with the density stratification observed between the two lowest CTDs at the channel location. Because the estimates of $\phi_{m}$ were noisy, the time series was smoothed using a locally weighted scatterplot smoothing (lowess) filter (Cleveland 1979) with an $8 \%$ window, after excluding all negative values. As a result, roughly $20 \%$ of the data were excluded before smoothing, mainly during periods of low current velocity. The smoothed time series of $\phi_{m}$ was compared with the time series of the vertical density stratification measured between the two adjacent CTDs that were closest in height to the mean height of the two functioning ADVs deployed at the channel site. Because of instrument noise and periodic erroneous measurements, and consistent with the time series measurements of $\phi_{m}$, the time series of stratification also was smoothed using a $8 \%$ "lowess" filter after excluding all values that reported unstable density stratification. Consistent with previous authors, we found a positive correlation between the departure from the law of the wall and the local density stratification $(r=0.76)$.

It follows from the analysis of the boundary layer shear at the channel site that the increased stratification on ebb due to tidal straining resulted in an intensification of ebb velocities throughout the water column relative to flood, given the same bottom stress $\left(u_{*}\right)$. At the channel site, the depth-averaged current magnitude is greater on ebb $\left(-0.41 \mathrm{~m} \mathrm{~s}^{-1}\right)$ than on flood $(0.33 \mathrm{~m}$ $\mathrm{s}^{-1}$ ). However, there was no strong lateral asymmetry in current magnitudes at peak flood or peak ebb, even during spring tides, when strong lateral shear was observed. This indicates that the preferential downestuary flow at the channel site was driven by lateral asymmetries in the duration of flood and ebb tides. The depth-averaged currents were ebb directed over $57 \%$ of the time at the channel site, as compared with roughly

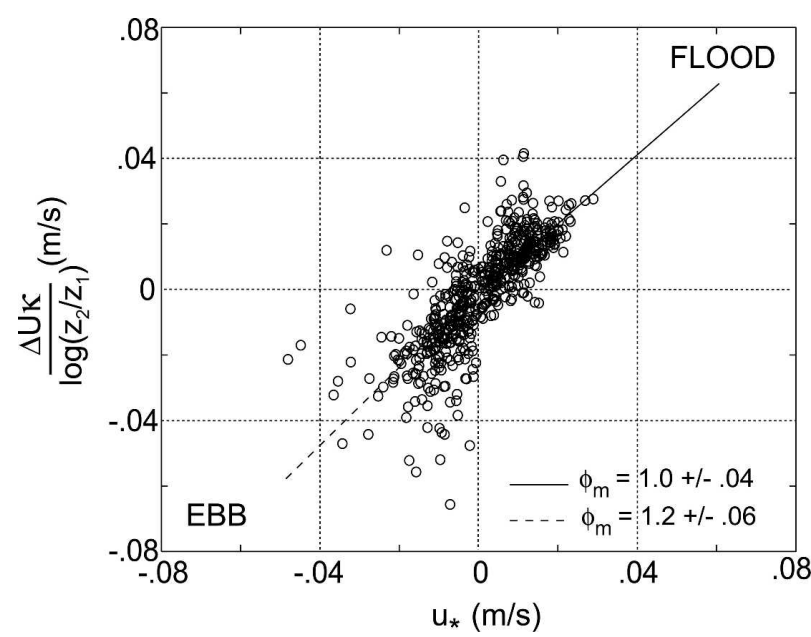

FIG. 4. Test of law of the wall using ADV data at channel site. Error estimates for $\phi_{m}$ correspond to one standard error. 


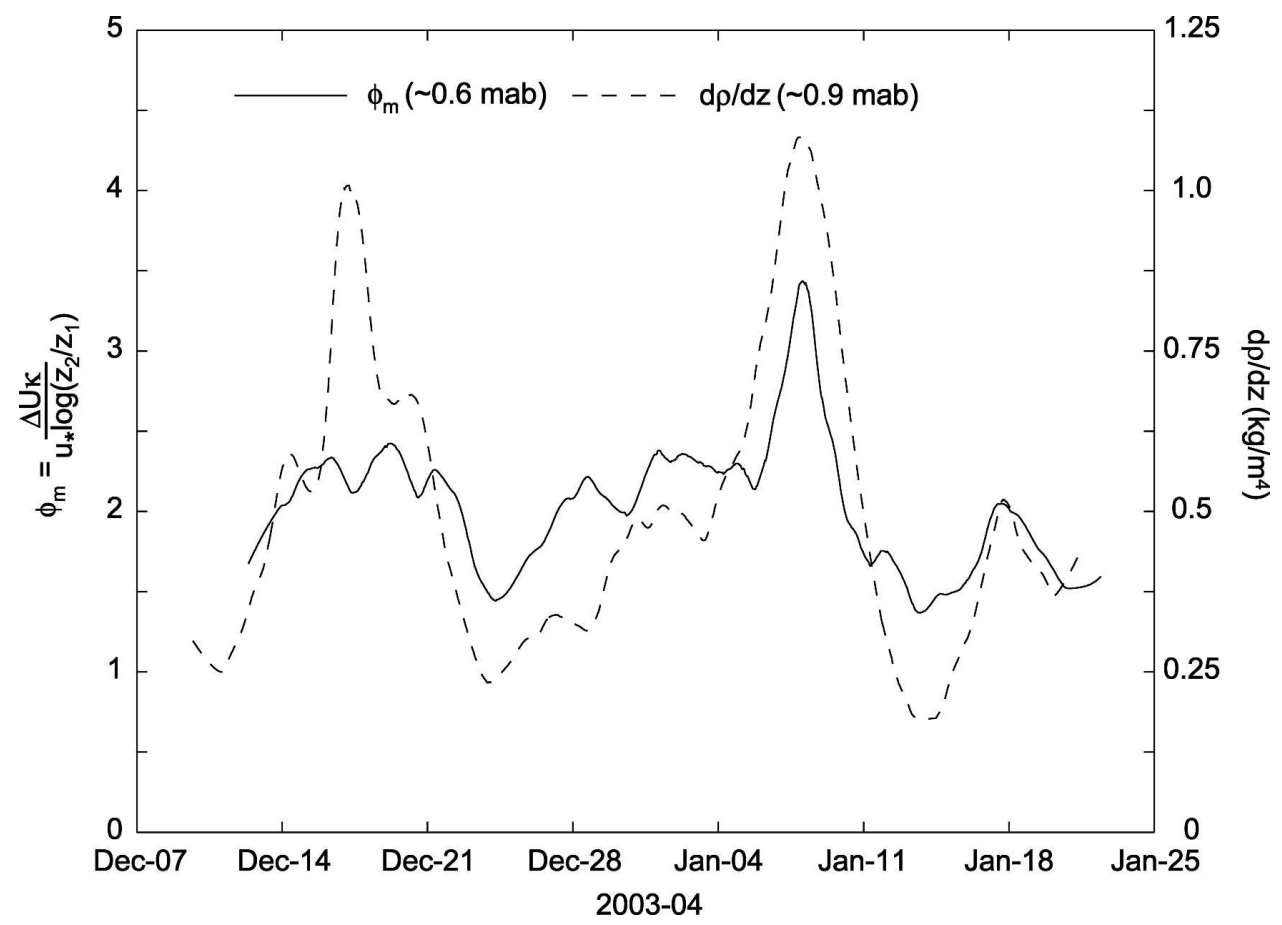

FIG. 5. Smoothed time series of $\phi_{m}$ estimated between the upper and lower ADVs (solid line) and density stratification measured between the two lowermost CTDs (dashed line), both at the channel site.

$52 \%$ of the time at the shoal site. This pattern was even more pronounced during spring tidal conditions. This lateral asymmetry in duration can be seen clearly by examining an average tidal cycle representation of the depth-averaged currents at both sites. The average tidal cycle values were calculated by dividing the entire time series into sections of length equal to the $M_{2}$ tidal period and then averaging all values with the same relative tidal phase. Figure 6 a shows the average tidal cycle values for the depth-average currents at both sites for the entire experiment. From this view, the lateral asymmetry in duration is clear. At the channel site the ebb tide was consistently longer than the ebb observed at the shoal site. This occurs because the transition from ebb to flood occurred much later at the channel site than at the shoal site, while the transition from flood to ebb occurred more simultaneously at both locations.

The lateral phase difference at the end of ebb appears to be related to both tidal and lateral asymmetries in turbulent mixing caused by changes in stratification. The average tidal cycle values of stratification at the channel and shoal sites are plotted in Fig. 6b. Consistent with the classic view of tidal straining, stratification at the channel site generally increased throughout the ebb tide, and decreased during the flood. The tidal pattern is less clear at the shoal site, which is generally less stratified than the channel consistent with the shallower bathymetry adjacent to the shoal site. Figure $6 \mathrm{c}$ plots the lateral difference in stratification between the two sites as a function of tidal phase. The data for spring and neap tidal conditions are plotted separately. The lateral difference in stratification was greater during spring tides than it was during neaps, even though the overall level of stratification was greater at both locations during neap conditions. This difference is particularly pronounced between the two locations at the end of ebb. This occurs because tidal straining generally creates stratification throughout the ebb at the channel site, while the mixing was sufficient to break down the stratification during peak ebb at the shoal location during spring tidal conditions. Given this lateral difference in stratification, the greatest lateral asymmetry in friction is assumed to have occurred during the later half of the ebb tide during spring tidal conditions. As a result, at the end of ebb the barotropic pressure gradient (which is assumed to be the same at both locations) is balanced to a greater extent by friction over the shoal than at the channel. With acceleration contributing more significantly to the dynamic balance at the channel location than the shoal, the tide begins flooding earlier over the shoals than at the channel. This lateral phase difference is not observed at the end of flood because the opposite sense of tidal straining reduces the lateral asymmetry in turbulent mixing. The net result of 


\section{a) Depth-Averaged Velocity}
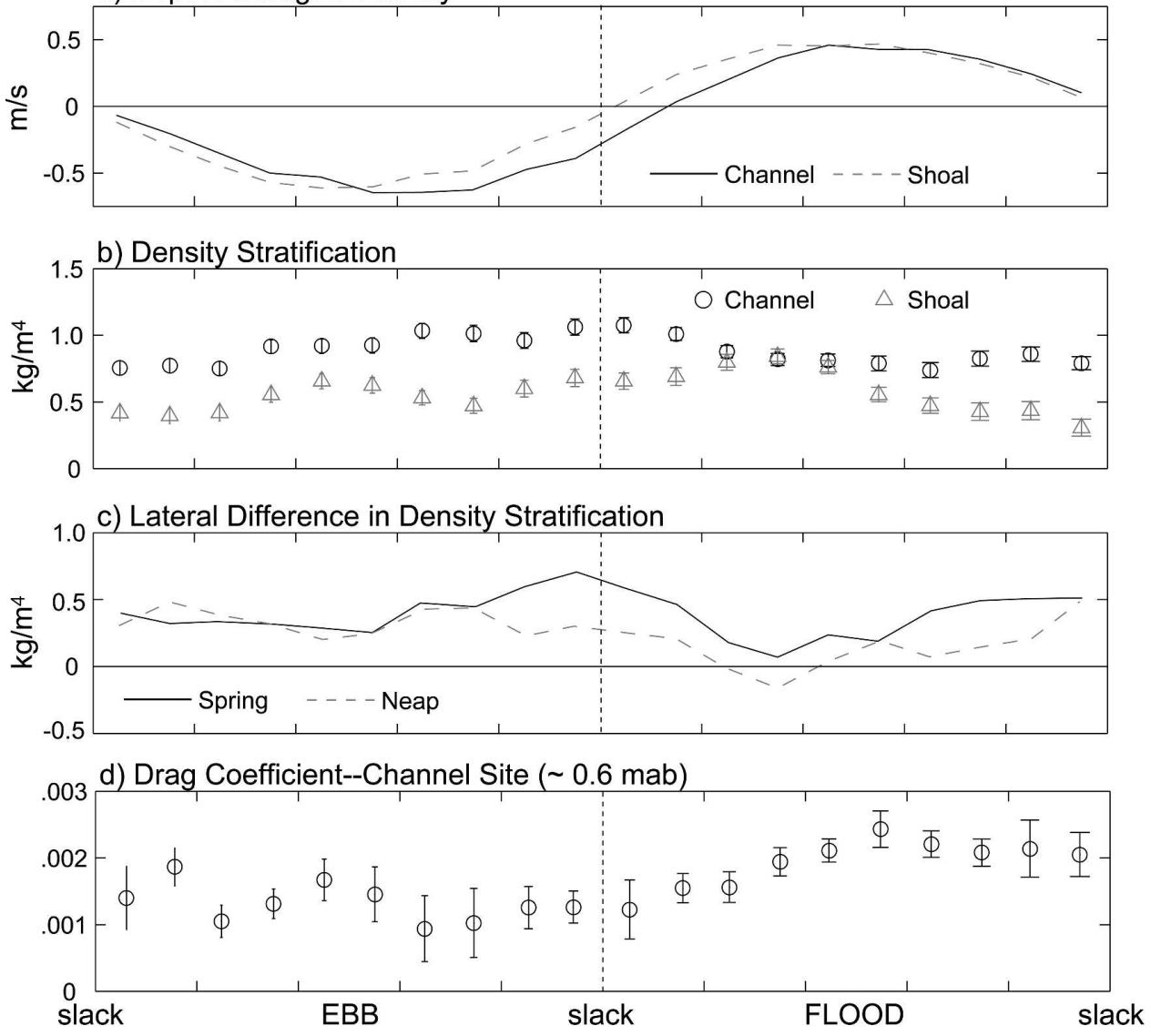

FIG. 6. Average tidal cycle values of (a) depth-averaged current velocities (solid line the channel site and dashed line the shoal site); (b) density stratification at the channel site (circles) and shoal site (triangles); (c) the lateral difference in stratification obtained by subtracting the stratification measured at the shoal site from the channel site for spring (solid line) and neap (dashed line) conditions; (d) drag coefficient calculated from ADV data at the channel site (vertical lines represent one standard error).

this pattern is to favor down-estuary residual flow over the deeper channel regions with residual inflow over the shoals.

A more direct examination of the impact that the tidal variations in stratification have on friction at the channel site can be examined using the ADV data to calculate a drag coefficient given as

$$
C_{D}=\frac{\tau_{b} / \rho}{u|u|},
$$

where $u$ is the velocity measured by the ADV $1.1 \mathrm{mab}$, and $\tau_{b}$ is calculated from the ADV data following Eq. (1). Figure 6d shows the average tidal cycle values of $C_{D}$ for the entire deployment at the channel site. There was a decrease in $C_{D}$ during the ebb tide, reaching a minimum value at the end of ebb. During the flood, the drag coefficient generally increased, reaching a maximum value near the end of flood. From this view, the drag coefficient was only slightly greater on flood than on ebb in the average sense. However, $C_{D}$ was over twice as large at the end of flood (0.002) than the end of ebb (0.001). This pattern is consistent with the tidal variations in stratification at the channel site and the general pattern of stratification expected as a result of tidal straining. Although no direct estimates of stress were available from the shoal site, we infer that the greatest lateral difference in internal mixing occurred at the end of ebb during spring tidal conditions, when the lateral difference in stratification was at its maximum value.

The impact of this inferred lateral difference in friction can be seen more clearly in Fig. 7, where the depthintegrated barotropic pressure gradient scaled by the tidal frequency $(\omega)$ is plotted against the depth-integrated transport for both sites. If the pressure gradient were balanced solely by friction, the data in Fig. 7 would fall roughly on a straight line (not exactly linear 

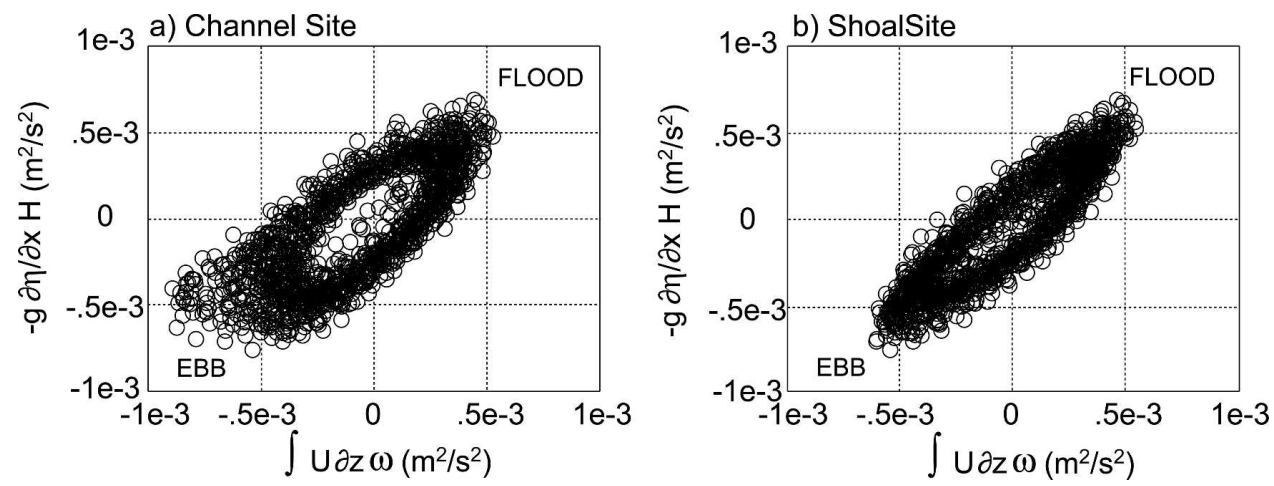

FIG. 7. Depth-integrated transport multiplied by the $M_{2}$ tidal frequency $(\omega)$ measured by the (a) ADCP at the channel site and (b) ADP at the shoal site plotted against the estimated depth-integrated barotropic pressure gradient.

because of the quadratic frictional dependence), while a frictionless balance between the pressure gradient and acceleration would appear as a circle. The most noticeable difference between the two sites occurred during the second half of the ebb tide, when the transport values at the channel site fall to the left of those for the shoal site. These data coincided with spring tidal conditions and mostly occurred during the period of 21-28 December, when the strongest lateral shear was observed. The data in Fig. 7 suggest that there was less friction to balance the pressure gradient during the later half of ebb at the channel site as compared with the shoal site.

\section{b. Momentum balance}

Although there were no direct measurements of stress at the shoal site, the stress at this location was estimated from the dominant terms in the momentum balance, as discussed above. Integration of Eq. (2) gave an estimate of the bed stress that could be compared with a quadratic drag representation of bed stress as expressed by Eq. (6). In general, the momentum estimate of near-bed stress was well correlated with the quadratic bottom velocity (Figs. $8 \mathrm{a}$ and $8 \mathrm{~b}$ ). The correlation coefficient, $r$, was 0.70 and 0.82 for the channel and shoal sites, respectively. However, there appeared to be both lateral and tidal asymmetries in the relationship between bottom velocity and bottom stress. These asymmetries can be seen clearly in the estimates of the drag coefficient. The drag coefficient was calculated using a least squares regression between the quadratic velocity and the momentum estimate of the bed stress. Flood and ebb data were treated separately and the regression was forced through the origin.

Consistent with ADV measurement, this analysis suggests that $C_{D}$ was consistently greater during the flood than the ebb tide at the channel site ( 0.0019 and 0.0011, respectively). At the shoal site, the tidal asymmetry was less pronounced and had the opposite sense, with a slightly lower $C_{D}$ on flood as compared with ebb (0.0023 and 0.0026 , respectively). This asymmetry is consistent with the overall greater degree of stratification observed at the channel site, as well as the patterns of tidal asymmetry in stratification that were observed. In addition to the tidal asymmetry in $C_{D}$, there were important lateral asymmetries as well. This was particularly evident during the ebb phase of the tide. While the estimate of $C_{D}$ during ebb was significantly greater at the shoal site than the channel site, the difference was much less pronounced during the flood phase of the tide. This pattern of lateral asymmetry is consistent with the observations that showed the tide reversing from ebb to flood significantly later at the channel site than the shoal site, but currents reversing from flood to ebb more simultaneously.

By using the momentum estimate of stress and the observed vertical velocity shear, profiles of the vertical eddy viscosity were estimated following:

$$
A_{z}=\frac{\left\langle u^{\prime} w^{\prime}\right\rangle}{\partial u / \partial z} .
$$

Figures $8 \mathrm{c}-\mathrm{f}$ show the estimates of the median vertical profiles of eddy viscosity for the two sites. The data were segregated by the phase of the tide as well as spring and neap tidal conditions. Depth-averaged values of eddy viscosity derived from the momentum balance are consistent with tidal and lateral asymmetries in stratification. In general, values of eddy viscosity were higher during spring tidal conditions and greater at the shoal site than at the channel site. At the channel site, where stratification was greater on average on the ebb phase of the tide, the depth-averaged eddy viscosity was consistently greater on flood as compared with ebb. 

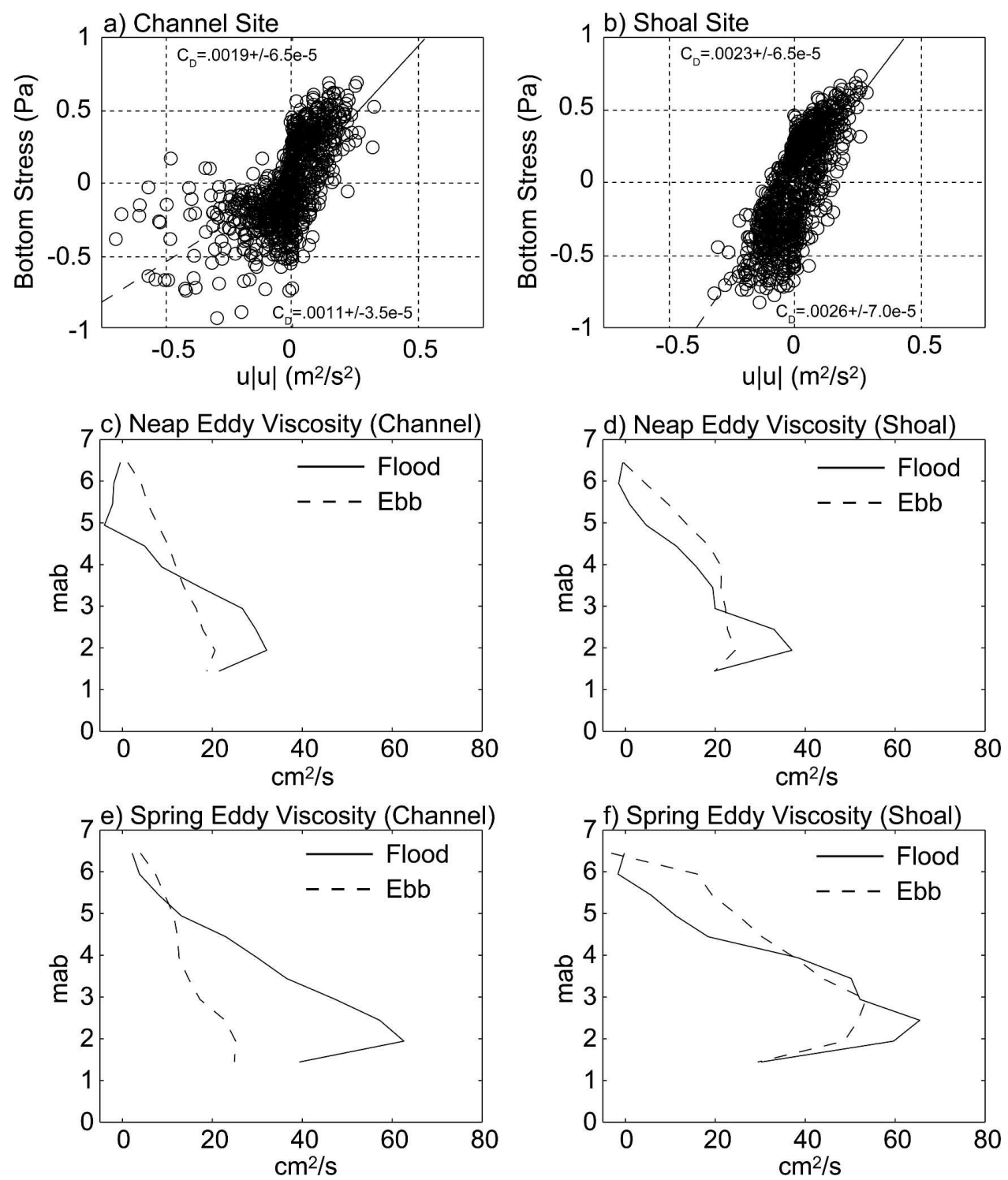

FIG. 8. Results from the along-channel momentum balance: scatterplot of estimated bed stress from the momentum integral and the quadratic velocity measured 1.4 mab for the (a) channel and (b) shoal sites; median profiles of the eddy viscosity estimated for both the (c), (e) channel and (d), (f) shoal sites during (c), (d) neap and (e), (f) spring tidal conditions (solid line denotes flood and dashed line denotes ebb).

The shoal site generally demonstrated the opposite pattern, consistent with the observed stratification at that location. Although tidal and lateral asymmetries were relatively weak during neap conditions, large asymmetries were present during spring tidal conditions. At the channel site, the depth-averaged eddy viscosity was nearly 2 times as large during the flood as during the ebb, despite strong down-estuary flows during this period. No significant tidal asymmetry was present at the shoal site, which led to a strong lateral asymmetry during the ebb phase of the tide.
The estimates of eddy viscosity from the momentum balance also were compared with the measured values from the ADVs at the channel site. Figure 9 shows a comparison between the time series of eddy viscosity measured by the ADV 0.6 mab and the momentum estimate of eddy viscosity that corresponds to the lowest bin of the ADCP (1.4 mab). Because there was noise in both the direct measurement and momentum estimate of eddy viscosity, especially near periods of low current magnitude, both time series were smoothed using a lowess filter with an $8 \%$ data window. Before 


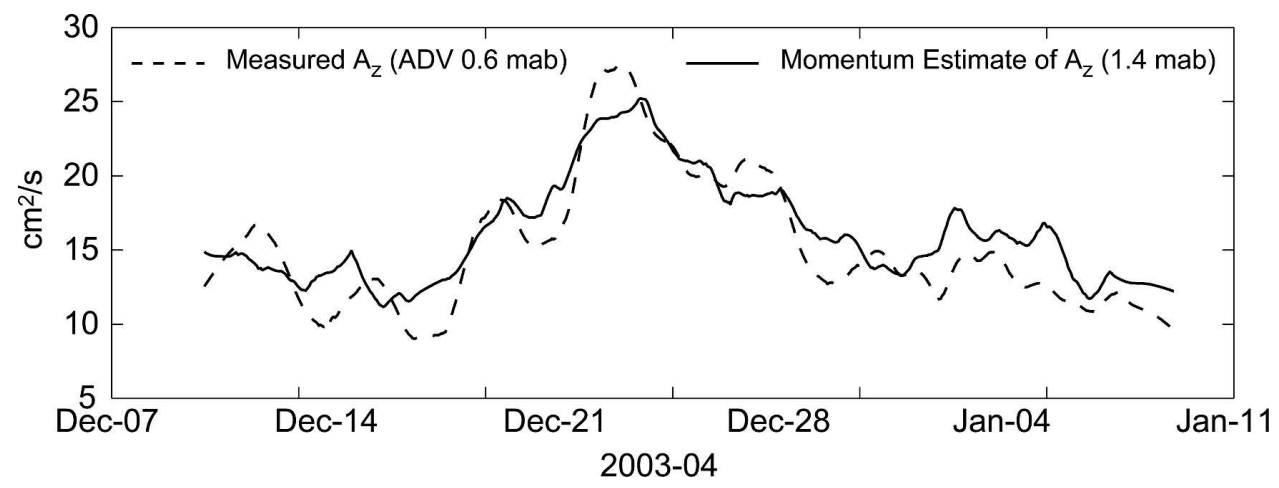

FIG. 9. Smoothed time series of the eddy viscosity at the channel site estimated from the momentum integral $1.4 \mathrm{mab}$ (solid line) and measured by ADVs $0.6 \mathrm{mab}$ (dashed line).

the smoothing was performed, all negative values and all values that exceed the maximum expected value for an unstratified boundary layer (i.e., $\kappa u_{*} z$ ) by more than $20 \%$ were removed. As a result, roughly $80 \%$ of the data were used for both the direct measurement and the momentum estimate of eddy viscosity. The good agreement between the magnitude and relatively high correlation between the time series of these two estimates of eddy viscosity provides confidence that the estimates of stress from the momentum integral are meaningful.

\section{c. 1D modeling results}

To illustrate more clearly the creation of residual flows due to internal asymmetries in mixing, a numerical experiment was conducted using the one-dimensional General Ocean Turbulence Model (GOTM). GOTM was run employing a $k$-epsilon turbulence closure scheme as described by Burchard and Bolding (2001) with the stability parameters of Canuto et al. (2001). The model was used to simulate a simple tidal flow, forced by a tidally varying barotropic pressure gradient and a depth-invariant along-channel salinity gradient $\left(\partial S / \partial x=3 \times 10^{-4} \mathrm{~m}^{-1}\right)$. The model was run for a depth of $10 \mathrm{~m}$, roughly consistent with the main channel of the York River, as well as a depth of $5 \mathrm{~m}$, generally consistent with the shoal region of the York River. A net seaward-directed barotropic pressure gradient was added so that the sum of the tidally averaged transport for the two depths resulted in no net volume transport. The net barotropic pressure gradient was imposed assuming that the shoal area ( $5 \mathrm{~m}$ deep) and the channel area (10 m deep) had equal cross-sectional areas, a pattern generally consistent with the bathymetry of the York River.

The model predicted a time-varying pattern of stratification where stratification was generally created during ebb and destroyed during flood at both the channel and shoal locations (Fig. 10a). The greatest stratification was predicted when velocity near the bed began to flood and the upper water column was still ebbing. This processes created significant stratification at the end of ebb that persisted into the flood, and as a result the flood tide was slightly more stratified on average than the ebb for the $10-\mathrm{m}$ simulation. However, the timevarying pattern of stratification predicted by the model exhibited the key feature that the end of ebb was significantly more stratified than the end of flood. Additionally, the stratification predicted over the lower half of the water column was over twice as large during the ebb, on average, as compared with the flood for the $10-\mathrm{m}$ simulation. The overall degree of stratification was lower for the 5-m location relative to the deeper 10-m location because, unlike at the deeper location, boundary layer mixing at the shallow location was capable of reaching all the way to the surface. As a result of the tidal asymmetry in stratification and internal mixing, the eddy viscosity was greater during the flood than during ebb (Fig. 10b). While this asymmetry was predicted at both the channel and shoal sites, it was more pronounced at the deeper location. Large lateral asymmetries in eddy viscosity in the upper portion of the water column were predicted, largely due to the inviscid conditions predicted in the upper water column at the channel site.

The profiles of residual circulation predicted by the model (Fig. 10c) are largely consistent with the observations from the York River. Relatively strong downestuary residual circulation was predicted over the upper portion of the water column for the channel location, relative to the shoal site. The depth-averaged residual circulation was down-estuary over the channel and up-estuary over the shoal despite the stronger integrated baroclinic forcing associated with the deeper location. A net up-estuary residual was predicted over the deepest portion of the $10-\mathrm{m}$ location. Again, we 


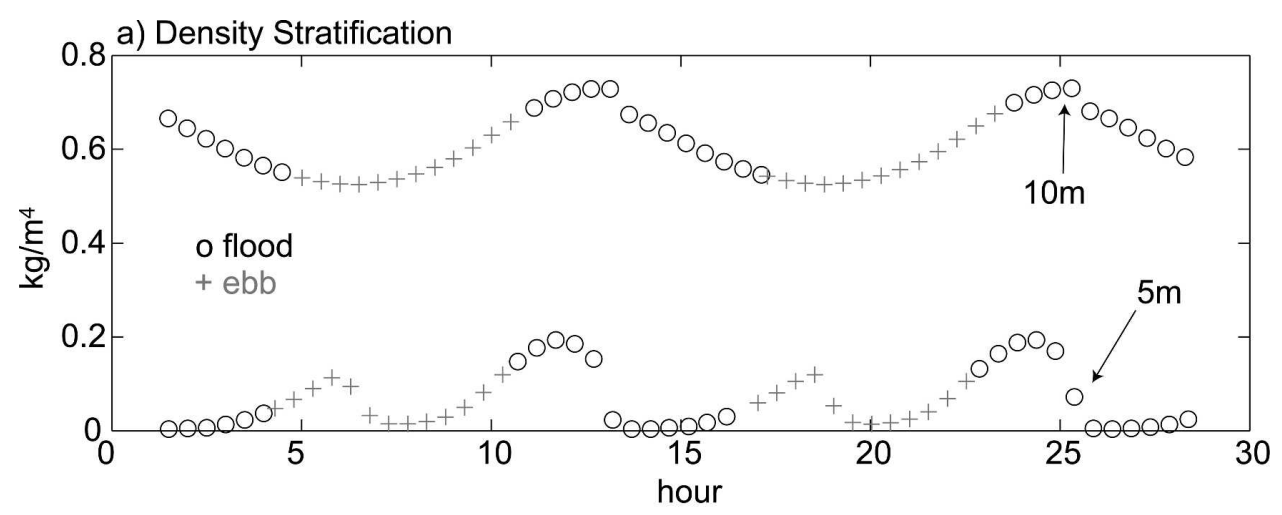

b) Eddy Viscosity

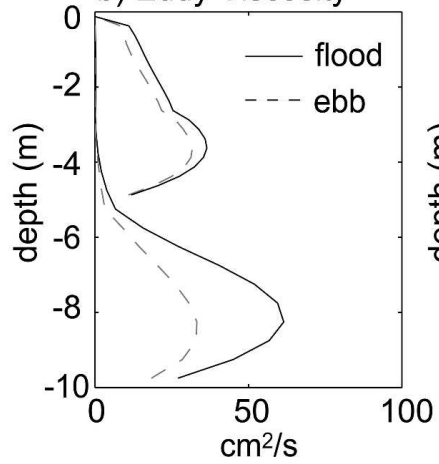

c) Residual Velocity

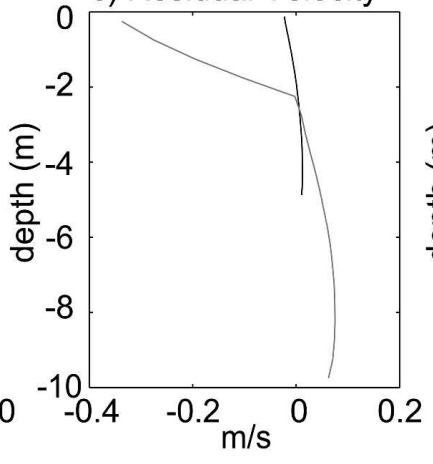

d) Resid. Vel. (No PG)

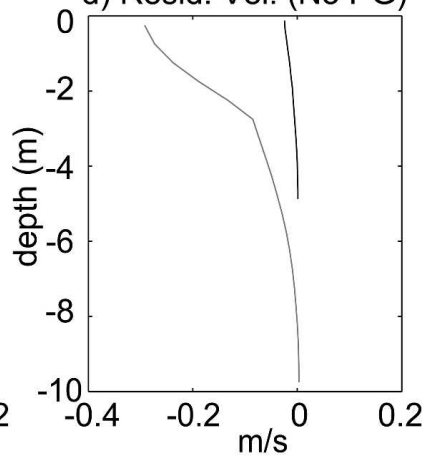

FIG. 10. Results from 1D turbulence model runs: (a) time series of density stratification predicted by the model for depths of 5 and $10 \mathrm{~m}$ (circles represent flood tide and crosses represent ebb tide); (b) median eddy viscosity profiles from model run with baroclinic and net ebb-directed barotropic pressure gradient (solid lines represent flood tide and dashed lines represent ebb tide); (c) along-channel residual velocity profile for model run with baroclinic and net ebb-directed barotropic pressure gradient; (d) along-channel residual velocity profile for model run with no baroclinic or net barotropic pressure gradient, but forced with tidal variations in salinity field. In (c) and (d), the dark line represents 5-m simulation and the light line represents $10-\mathrm{m}$ simulation.

assume a similar residual inflow occurred over the deepest part of the channel in the 2003/04 experiment, but was not resolved because of the instrument locations. Although the predicted ebb velocities at the channel location are larger than both the flood velocities at the channel and the ebb velocities on the shoal, much of the down-estuary residual at the channel site is caused by longer relative duration of the ebb tide. Consistent with the observations, both the lateral and vertical phase differences were significantly larger during the transition from ebb to flood than during the transition from flood to ebb. This is largely a consequence of the reduced friction at the end of ebb caused by tidal straining of the density field, which delays the onset of the ebb tide in the channel.

It is important to note that in order to have zero net flow through the estuarine cross sections over the tidal cycle it was necessary to impose a net ebb-directed barotropic pressure gradient. This is consistent with the classic analytical solution for density-driven estuarine circulation (e.g., Officer 1976). However, the pattern of tidal asymmetries in the vertical density stratification, which lead to increased vertical velocity shear during the ebb tide, reduced the net barotropic pressure gradient significantly from the value predicted analytically. In fact, the net ebb-directed barotropic pressure gradient necessary to ensure no net volume transport through the cross section was nearly $70 \%$ smaller than that predicted based on the Officer (1976) solution (i.e., $\partial \eta / \partial x=-3 h / 8 \rho \partial \rho / \partial x$ for case with negligible river flow).

The role that tidal asymmetries in mixing play in the modification of the net barotropic pressure gradient can be clearly demonstrated with another simple numerical experiment. The model was next run imposing the time-varying salinity field from the first model run, but artificially setting the baroclinic pressure gradient to zero. To highlight the role of asymmetries in mixing, no net barotropic pressure gradient was used. The resulting residual circulation profiles are presented in Fig. 
10d. Clearly the time-varying pattern of stratification leads to strong down-estuary residual flows, as no baroclinic or net barotropic pressure gradient forcing was used in this simulation. Of course in a real estuary, the net barotropic pressure gradient would adjust to account for this net volume transport in order to conserve mass. The important role that tidal asymmetries in mixing have on the residual velocity is demonstrated in the profiles shown in Fig. 10d, which have nearly the same vertical form as those presented in Fig. 10c despite no baroclinic forcing. This result suggests that the twolayer structure of the residual estuarine circulation is driven largely by the interaction of tidal asymmetry and the barotropic tide. The along-channel density gradient is necessary to create the asymmetries in stratification that drive this process; however, the process itself is largely barotropic in nature.

\section{Discussion}

The results from the 1D model simulations, which suggest that the majority of the vertical shear in the residual velocity profile is generated by tidal asymmetries in mixing and not directly by the baroclinic pressure forcing, are generally consistent with the mechanism proposed by Jay and Musiak (1994). However, it is important to note that in both the observations and modeling results, the near-bed intensification of the landward velocity is not the result of convective mixing during the flood, but is caused by the modification of the net barotropic pressure gradient. This occurs because the ebb velocity profile is more sheared than the flood throughout the water column, which leads to an asymmetry in transport that must be balanced barotropically. While the barotropic pressure gradient responds to the integrated transport through the entire estuarine cross section, the vertical velocity shear responds locally to the degree of turbulent mixing. As a result, distinct laterally sheared residual flows can develop in systems that exhibit both tidal and lateral asymmetries in mixing due to changes in the transverse bathymetry. In systems with more uniform lateral bathymetry, it is likely that tidal asymmetries in stratification will act more or less uniformly across the estuary, leading to a vertically segregated two-layer residual. The data from the York River suggest that the residual lateral shear is modulated over the springneap transition. Significant lateral shear is observed during spring conditions because this is when the greatest lateral difference in stratification was observed (Fig. 6c).

While this mechanism is related to asymmetries in stratification caused by tidal straining of the along- channel density gradient, it is a barotropic process nonetheless. The baroclinic forcing will act to offset the lateral pattern of residual circulation described above by favoring inflow over the channel areas with outflow over the shoals (Wong 1994; Kasai et al. 2000; ValleLevinson et al. 2003). The large impact of lateral asymmetries in mixing in this experiment was highlighted because the relatively similar depths at the two instrumented locations negated significant difference in baroclinic forcing. Had our instrumentation been deployed in the deepest portion of the channel, the impact of the lateral asymmetries in mixing may have been more difficult to isolate. In fact, the large lateral phase difference we observed at the end of ebb may have been reduced or even reversed had we measured the flow in the deepest portion of the channel where the impact of the baroclinic pressure gradient may have caused the tide to turn from ebb to flood sooner because of the increased magnitude of the baroclinic pressure gradient.

Separating the barotropic and baroclinic contributions to residual circulation is difficult. Li et al. (1998) attempted to separate the barotropic and baroclinic components of the residual circulation in the James River and found the barotropic residual to exhibit outflow over the channel with inflow on the shoals, with the baroclinic residual displaying the opposite pattern. Although their analysis was kinematic and they did not identify the physical mechanism driving the flow, the James River is dynamically similar in many ways to the York River, and the barotropic residual described by $\mathrm{Li}$ et al. (1998) is consistent with the mechanism described in this paper. However, there are a number of other barotropic mechanisms that can generate a similar lateral distribution of residual flow. In systems with laterally varying bathymetry, tidal rectification of stokes drift (Li and O'Donnell 1997) or the nonlinear advective terms in the momentum equation (Winant and Gutierrez de Velasco 2003) can result in a laterally sheared barotropic residual. It is important to note that the mechanism detailed in this paper is fundamentally different from either of these processes because it arises from tidal asymmetries in internal mixing. However, it is analogous in some respects because it involves the rectification of asymmetric transport driven by tidal nonlinearities. It is unlikely that these other nonlinear processes play an important role in the data discussed above. The contribution of stokes drift in the York River can be estimated from the data and was only on the order of $1 \mathrm{~cm} \mathrm{~s}^{-1}$, consistent with the results of Friedrichs and Hamrick (1996) for the James River. Additionally, estimates of the nonlinear advective terms from the data are not consistent with pattern of 
residual circulation described by Winant and Gutierrez de Velasco (2003) or Lerczak and Geyer (2004).

\section{Conclusions}

This study demonstrates the importance of asymmetries in mixing associated with tidal straining to residual estuarine circulation. The presence of stratification causes the shear in the boundary layer to deviate from the expected law of the wall relationship. This deviation is strongly correlated with the strength of the observed density stratification. As a result, tidal asymmetries in stratification lead to increased shear during the more stratified phase of the tide. When the expected pattern of tidal straining is observed, the increased shear during the ebb tide favors down-estuary transport that must be balanced barotropically in order to conserve mass over the tidal cycle. When tidal asymmetries act uniformly across an estuary and there are no significant lateral gradients in turbulent mixing, this will result in a vertically segregated two-layered exchange flow. However, many drowned river valley estuaries have channelshoal bathymetries that lead to lateral variability in density stratification and turbulent mixing. As a result, tidal straining can significantly increase density stratification during the ebb tide over deeper areas, while shallower areas remain relatively well mixed. This results in large lateral variations in friction, causing the tide to turn from ebb to flood considerably earlier on the shoals than in the channel. This increases the duration of the ebb tide over the channel and favors downestuary residual flow that is balanced by residual inflow over the shoals.

Acknowledgments. The authors thank Grace Cartwright, Todd Nelson, Bob Gammisch, Frank Farmer, Sam Wilson, Wayne Reisner, and Don Wright for their assistance with the preparation, deployment, and retrieval of the instrumentation used in this experiment. Willy Reay kindly provided the YSI 6000s used in the experiment. This manuscript benefited from the helpful comments of two anonymous reviewers. Support for this research was provided by the National Science Foundation Division of Ocean Sciences Grant OCE9984941.

\section{REFERENCES}

Burchard, H., and K. Bolding, 2001: Comparative analysis of four second-moment turbulence closure models for the oceanic mixed layer. J. Phys. Oceanogr., 31, 1943-1968.

Businger, J. A., J. C. Wyngaard, Y. Izumi, and E. F. Bradley, 1971: Flux-profile relationships in the atmospheric surface layer. $J$. Atmos. Sci., 28, 181-189.
Canuto, V. M., A. Howard, Y. Cheng, and M. S. Dubovikov, 2001: Ocean turbulence. Part I: One-point closure model-Momentum and heat vertical diffusivities. J. Phys. Oceanogr., 31, 1413-1426.

Cleveland, W. S., 1979: Robust locally weighted regression and smoothing scatterplots. J. Amer. Stat. Assoc., 74, 829-836.

Friedrichs, C. T., and J. M. Hamrick, 1996: Effects of channel geometry on cross-sectional variations in along-channel velocity in partially stratified estuaries. Buoyancy Effects on Coastal and Estuarine Dynamics, D. G. Aubrey and C. T. Friedrichs, Eds., Coastal and Estuarine Studies, Vol. 53, Amer. Geophys. Union, 283-300.

_ L. D. Wright, D. A. Hepworth, and S. C. Kim, 2000: Bottom boundary layer processes associated with fine sediment accumulation in coastal seas and bays. Cont. Shelf Res., 20, 807841.

Geyer, W. R., J. H. Trowbridge, and M. M. Bowen, 2000: The dynamics of a partially mixed estuary. J. Phys. Oceanogr., 30, 2035-2048.

Huzzey, L. M., and J. M. Brubaker, 1988: The formation of longitudinal fronts in a coastal plain estuary. J. Geophys. Res., 93, 1329-1334.

Jay, D. A., and J. D. Musiak, 1994: Internal tidal asymmetry in channel flows: Origins and consequences. Mixing in Estuaries and Coastal Seas, C. Pattiaratchi, Ed., Coastal and Estuarine Studies, Vol. 50, Amer. Geophys. Union, 211-249.

Kasai, A., A. E. Hill, T. Fujiwara, and J. H. Simpson, 2000: Effect of the earth's rotation on the circulation in regions of freshwater influence. J. Geophys. Res., 105, 16 961-16969.

Kim, S.-C., C. T. Friedrichs, J. P.-Y. Maa, and L. D. Wright, 2000: Estimating bottom stress in tidal boundary layers from acoustic Doppler velocimeter data. J. Hydraul. Eng., 126, 399-406.

Large, W. G., and S. Pond, 1981: Open ocean momentum flux measurements in moderate to strong winds. J. Phys. Oceanogr., 11, 324-336.

Lerczak, J. A., and W. R. Geyer, 2004: Modeling the lateral circulation in straight, stratified estuaries. J. Phys. Oceanogr., 34, $1410-1428$.

Li, H., and J. O'Donnell, 1997: Tidally induced residual circulation in shallow estuaries with lateral depth variation. J. Geophys. Res., 102, 27 915-27 929.

_ A. Valle-Levinson, K. C. Wong, and K. M. M. Lwiza, 1998: Separating baroclinic flow from tidally induced flow in estuaries. J. Geophys. Res., 103, 10 405-10 417.

Officer, C. B., 1976: Physical Oceanography of Estuaries (and Associated Coastal Waters). John Wiley and Sons, $465 \mathrm{pp}$.

Pritchard, D. W., 1956: The dynamic structure of a coastal plain estuary. J. Mar. Res., 15, 33-42.

Rippeth, T. P., N. R. Fisher, and J. H. Simpson, 2001: The cycle of turbulent dissipation in the presence of tidal straining. $J$. Phys. Oceanogr., 31, 2458-2471.

Scully, M. E., and C. T. Friedrichs, 2003: The influence of asymmetries in overlying stratification on near bed turbulence and sediment suspension in a partially mixed estuary. Ocean Dyn., 53, 208-219.

,-- , and J. M. Brubaker, 2005: Control of estuarine stratification and mixing by wind-induced straining of the estuarine density field. Estuaries, 28, 321-326.

Simpson, J. H., J. Brown, J. Matthews, and G. Allen, 1990: Tidal straining, density currents, and stirring in the control of estuarine stratification. Estuaries, 13, 125-132.

— , E. Williams, L. H. Brasseur, and J. M. Brubaker, 2005: The 
impact of tidal straining on the cycle of turbulence in a partially stratified estuary. Cont. Shelf Res., 25, 51-64.

Smith, J. D., and S. R. McLean, 1977: Spatially averaged flow over a wavy surface. J. Geophys. Res., 82, 1735-1746.

Soulsby, R. L., and K. R. Dyer, 1981: The form of the near-bed velocity profile in tidally accelerating flow. J. Geophys. Res., 86, 8067-8074.

Stacey, M. T., S. G. Monismith, and J. R. Burau, 1999: Observations of turbulence in a partially stratified estuary. J. Phys. Oceanogr., 29, 1950-1970.

- J. R. Burau, and S. G. Monismith, 2001: Creation of residual flows in a partially stratified estuary. J. Geophys. Res., 106, 17 013-17 037.
Trowbridge, J. H., W. R. Geyer, M. M. Bowen, and A. J. Williams, 1999: Near-bottom turbulence measurements in a partially mixed estuary: Turbulent energy balance, velocity structure, and along-channel momentum balance. J. Phys. Oceanogr., 29, 3056-3072.

Valle-Levinson, A., C. Reyes, and R. Sanay, 2003: Effects of bathymetry, friction, and rotation on estuary-ocean exchange. J. Phys. Oceanogr., 33, 2375-2393.

Winant, C. D., and G. Gutierrez de Velasco, 2003: Tidal dynamics and residual circulation in a well-mixed inverse estuary. $J$. Phys. Oceanogr., 33, 1365-1379.

Wong, K.-C., 1994: On the nature of transverse variability in a coastal plain estuary. J. Geophys. Res., 99, 14 209-14 222. 